\title{
How and Why to Teach English Metaphors to Japanese Learners Through Visual Media: With Practical Examples From Steven Universe
}

\author{
Spring, Ryan · Suarez, Gerard* \\ (Tohoku University · University of the Philippines Diliman)
}

\begin{abstract}
Spring, Ryan \& Suarez, Gerard. (2018). How and why to teach English metaphors to Japanese learners through visual media: With practical examples from Steven universe. STEM Journal, 19(4), 109-126.
\end{abstract}

Teaching conceptual metaphors to EFL learners has been shown to help with their learning of vocabulary and expressions, but this can be difficult for L1 Japanese EFL learners because of cultural and linguistic differences in the two languages. In teaching metaphors, the Cognitive Theory of Multimedia Learning and understanding of the theory of mental spaces can be used to argue that using visual media is particularly helpful for English learners. This paper presents a case that teaching conceptual metaphors is important for L1 Japanese learners of English, but difficult because of the large number of differences in the metaphorical expressions of the two languages, though these problems can be overcome through visual media, particularly animations. It suggests that they can be especially helpful when attempting to teach new conceptual metaphors to EFL learners because of their multi-modal nature and the ease with which they can construe reality. The paper further argues that animations aimed at children, such as Steven Universe, are particularly helpful because the metaphors are often made especially easy to understand, are often shown in an appropriate cultural context. Furthermore, Steven Universe has recurring themes built upon conceptual metaphors, allowing instructors to find many examples of the same metaphors.

\section{INTRODUCTION}

Japanese learners of English have a number of obstacles to overcome when learning English as a foreign language. Aside from the obvious linguistic differences in the two languages, from syntax and semantics to pronunciation (Ohata, 2002; Swan \& Smith,

${ }^{*}$ Co-authors: Spring, Ryan; Suarez, Gerard 
1987; Tsunoda, 2009), there are a number of higher level differences that can be more difficult to overcome, such as cultural differences and differences in cognitive linguistic aspects such as focus and categorization (Berendt, 2008; Spring, 2015; Uehara, 1998). While Spring (2015) provided several examples of how surrounding cultural and cognitive differences can create trouble for the second language acquisition of English by Japanese L1 learners, he did not go into great detail on any of these issues, and left several other differences unmentioned. One such difference is that of metaphor. Metaphorical expressions can have subtle differences that cause difficulty in understanding them in an L2, and careful instruction from the teachers has been found to be helpful (Hiraga, 2008; Sakui \& Gaies, 2006; Yasuda, 2010). This paper aims to detail how lack of knowledge of cross-cultural differences between metaphors can cause problems for Japanese learners of English (henceforth L1 Japanese EFL learners), through specific examples of metaphors that are particularly problematic for them, and posits that video, especially animation, is an effective way of teaching these metaphors to them because they show simultaneous multi-modal manifestations of the same metaphor, making it easier to understand, and offer the teacher a unique way to show the specifics of the metaphor within a given cultural setting. Specific examples of how this can be done are also given from the animation, Steven Universe (Sugar, 2013), to illustrate the points and provide ideas for practical implementation. Steven Universe was chosen as a case study because it is an animation, which in general, allows for conceptual metaphors to be easily depicted, aimed at children, which means the metaphors are made very easy to understand for the audience, and because it has recurrent themes, which helps instructors to find several consistent examples of the same metaphor.

\section{LITERATURE REVIEW}

\section{Manifestations of Conceptual Metaphors}

According to Lakoff and Johnsen (2003), there is a difference between conceptual metaphor and metaphorical expressions. Conceptual metaphors are systematic patterns of thought where one concept is understood in terms of another. These structures underpin how people conceptualize, speak about and relate to the world. For example, Lakoff and Johnsen (2003) give ARGUMENT IS WAR as the underlying structure that English speakers use to understand the concept of an argument. From this underlying concept, various forms of linguistic expressions arise - idioms or figures of speech perhaps but more interestingly, expressions which seem "common-sensical" in the native language. For example, from the conceptual metaphor ARGUMENT IS WAR, we arrive at 
metaphorical expressions such as 'your claims are indefensible', 'he attacked every weak point in my argument', and 'his criticisms were right on target'. Thus, though these sentences may not seem connected on the surface, they illustrate how arguments are normally discussed and thought about: as a war or conflict.

Conceptual metaphors influence not only word choice for metaphoric expression, but also what visual or audio representations are used in multi-media such as images, music, videos and gestures, etc. (Forceville \& Urios-Aparisi, 2009; Suarez, 2017). Visual media, such a movie or animation, is generally multi-modal in nature and thus relies on a number of different messages working in tandem to create a central message. Because of this, when conceptual metaphors are expressed in visual media, they often manifest not only in the linguistic expressions used, but also in the other modes available in the medium of film. For instance, Suarez (2017) showed how the conceptual metaphors LOVE IS UNITY and LOVE IS AN ECONOMIC EXCHANGE manifest in television's various modalities (visual, musical and speech) within the American cartoon, Stephen Universe, and also described how these individual modalities come together to deliver a coherent and consistent idea about relationships during an extended period of time. One example he gave was at the end of the web episode Fusion (Mitroff, 2017), where the word love was used to respond to a question. At the same moment, moving hearts were added in the background, the speaking characters merged together and posed to form a heart with their hands, the word itself was spoken with a rising intonation, and the previously playing neutral music was cut and replaced with the sound of a harp being played in a rising tone. Each of these, presented together in that particular instance, emphasized the idea that love was most important reason for undergoing the act of fusion; a thematic action in the series in which two or more characters physically combine themselves to become a singular entity. The act of fusion itself is a metaphor for love, the act resulting in a new character that combines the physical attributes of the two individuals, such as in the example of a red character and a blue character that combine to form a purple colored character that is roughly double the size of the two individual characters and has extra body parts to reflect the merge. This clearly expresses the conceptual metaphor LOVE IS UNITY - visually through the combination of and addition of physical traits to the new fused form, musically through the combination of instruments representing the characters (e.g. a character that is represented by piano and another represented by a synthesizer forms a character which is represented by both instruments), and verbally through the spoken descriptions of the process of fusion and the altered tone of voice of the two merged characters (e.g. two individual characters that were referred to separately as they become referred to with the singular you after the act). On the other hand, failed or dysfunctional fusions within the show are depicted in a different way. In one instance for example, characters which are fused are depicted bound together in chains, both struggling for control to dominate and 
control the other. Further, when characters in these instances of fusion discuss their association, it is discussed in terms of what one can gain from the other (e.g. more power) without necessarily taking into account what the other wants. In these cases, conceptual metaphor LOVE IS AN ECONOMIC EXCHANGE pervades and thus the show depicts two variations on the conception of love within the American context.

Differing instances can be found in the work of Forceville and Urios-Aparisi (2009), who gave the example of a car commercial which created the metaphor of CAR IS A LONG-JUMP ATHLETE. The metaphor was expressed through a visual montage, crosscutting shots of a track-and-field athlete with similar parts of the car (e.g. the first shot shows the athlete tying their shoe laces, the second shot shows the driver fastening their seatbelt), which "...enhances the identification of the target with its source" (p. 100). Metaphor in this instance is unique in that it was constructed just for the purposes of the commercial, not necessarily being connected to other conceptions of cars or athletes. On the other hand, Forceville and Urios-Aparisi (2009) also presented research which showed how conceptual metaphors affect a genre. For example, they suggested that in many horror films, the metaphor HUMAN VICTIM IS ANIMAL is expressed in a number of ways. They present an example in which the victims in one movie are seen driving on a road passing through a kangaroo crossing sign which has a bullet hole through it. For a brief moment, we can see the victim's car through the hole in the sign, thus juxtaposing the two - the victim is the kangaroo. This juxtaposition is constantly presented throughout the rest of the film both (i) visually (e.g. cross-cutting footage of kangaroos and the victim sideby-side just before a victim is killed, victims are tortured in a cage, etc.) and (ii) verbally (e.g. the killer implicitly likens his victims to kangaroo vermin that are everywhere).

In sum, multimodal metaphors such as these are pervasive in various forms of visual media and surface in a wide variety of ways within the different modalities available in that form of media, such as those described above. Further, these metaphors can vary in the range of their pervasiveness; they may appear only for a specific instance, such as the case of the car commercial, they may be recurring and appear in various iterations within a particular piece, as was the case in Steven Universe representing conceptions of love, or they may be pervasive across a particular genre, as was the case of HUMAN VICTIM IS ANIMAL surfacing in different horror films.

\section{Differences in Conceptual Metaphors}

Though some conceptual metaphors are found to be the same cross-linguistically because they are based on the human experience, which is the same regardless of culture (Nabeshima, 2011), others that are built on a culture or language-community's commonly held beliefs vary greatly (Kövecses, 2005). For example, the conceptual metaphor FEAR 
IS COLD is due to the fact that when scared, the human body will drop in temperature, and thus, metaphoric expressions built on this idea are pervasive in most languages (Nabeshima, 2016). On the other hand, some conceptual metaphors are found in only certain cultures or languages, such as two of the common conceptual metaphors for love in English: LOVE IS UNITY and LOVE IS AN ECONOMIC EXCHANGE (Kövecses, 2005). These conceptual metaphors are built based on ideas that English speakers had or have of love, which are often quite different from other languages, particularly Japanese, as exemplified below. For example, while Japanese shares conceptual metaphors about relationships which are similar such as LOVE IS CLOSENESS, it does not share the metaphor of economic exchange, and further, has its own metaphors not found in English such as LOVE IS THICKNESS (Nabeshima, 2011). Such cross-cultural variation of conceptual metaphors presents potential problems for second language learners in two main ways. First, while conceptual metaphors may be almost equivalent in a learner's L1 and L2, they often have subtle but significant differences, which cause differences in expression. Second, some conceptual metaphors do not exist in the L2.

Since Japanese and English have a large cultural and linguistic distance (Spring, 2015; amongst many others), there are many differences in the base ideas surrounding shared conceptual metaphors. For example, both languages share the metaphor ANGER IS THE HEAT OF A FLUID CONTAINER. Examples of this conceptual metaphor manifesting in metaphorical expressions are given in Japanese and English in (1a-f). Because English and Japanese share this conceptual metaphor, English expressions such as those in (1d-f) are likely easy for Japanese EFL students to understand, and expressions such as (1c) are likely not as difficult for them to express, because they are rather easily transferred from their L1.

(1) a. Harawata ga niekurikaeru. '(His/her) intestines are boiling.'

b. Atama kara yuge ga tatsu. 'Steam rises from the head.'

c. Haha wa toutou bakahatsu shita.

'My mother finally exploded'

d. She was boiling with anger.

e. He had steam coming out of his ears.

f. She exploded at me.

(Examples [1a-c] from Matsuki, 1995, pp. 140-141)

However, regardless of the fact that the conceptual metaphor exemplified in (1) is shared in Japanese and English, there are subtle differences. For example, the Japanese 
version of anger has a component of intensity correlated to a directionality element; anger starts from the belly (hara) where it is not as intense, then travels to the chest/heart (mune), where it has built up and is rising, and then reaches its apex of intensity in the head (atama), where it is finally at its utmost limit. Sentences that follow this structure make sense to Japanese native speakers, and also convey a gravity to the notion that the English metaphor does not. This can therefore cause confusion if a learner tries to directly transfer L1 expressions such as those in (2a-c) into English.

(2) a. Hara ga tatsu.

'Belly rises up.'

b. Hara ni osameteoku.

'Hold it in the belly.'

c. Toutou ni atama ni kita.

'Finally (it) has come to the head.'

Another example of subtle differences in a shared metaphor between Japanese and English causing difficulty for L1 Japanese EFL learners is with metaphors which structure the notion of marriage. For example, Dunn (2004) finds that while marriage is understood and spoken about as a “...joint creation, a union and a journey...” (p. 356) in both Japanese and American cultures, both models subtly differ in how the nature and direction of the work of marriage is discussed. For example, in American culture, there is an idea that marriage can be negative and/or forced upon a party, whereas this is not a concept very familiar in Japanese culture. Therefore, metaphors such as those in (3a-c) might be difficult for L1 Japanese EFL learners.

(3) a. They had a shotgun wedding.

b. She is my ball and chain.

c. He got out of his marriage.

Though subtle differences in shared metaphors can cause problems for L1 Japanese EFL learners, as detailed above, it is also problematic when conceptual metaphors are not shared. For example, heart/mind (kokoro) is often expressed in Japanese as relating to water, as in expressions such as in (4a\&b) (Yamanaka, 2008). However, these metaphors cannot be transferred to L2 English, as this conceptual metaphor does not exist.

(4) a. kokoro-asashi

'(his) heart is shallow' - (He doesn't try hard enough or have enough passion) 
How and Why to Teach English Metaphors to Japanese Learners Through Visual Media:

With Practical Examples From Steven Universe

b. kokoro ga yodomu

'(my) heart stagnates' - (I am hesitating or faltering)

Similarly, there are conceptual metaphors in English that do not exist in Japanese, such as the MIND IS A MACHINE and the MIND IS A BRITLE OBJECT. Naturally, expressions that stem from these conceptual metaphors, such as those shown in (5a-d) and (6a-d) respectively, will be among the most difficult for L1 Japanese EFL learners to acquire because the underlying conceptual metaphor does not exist in the L1, and thus this idea is unavailable for transfer.

\section{MIND IS A MACHINE}

(5) a. We're still trying to grind out the solution to this equation.

b. My mind just isn't operating today.

c. Boy, the wheels are turning now!

d. I'm a little rusty today.

\section{MIND IS A BRITLE OBJECT}

(6) a. Her ego is very fragile.

b. You have to handle him with care since his wife's death.

c. He broke under cross-examination.

d. His mind snapped.

(Adapted from Lakoff \& Johnsen, 2003)

While these examples are surely not the only problematic metaphors for L1 Japanese EFL learners, they are representative of the problem because they either contain subtle differences in conceptual metaphor or exhibit a lack of conceptual metaphor in their L1 that can transfer to L2 English. Furthermore, while some of these examples may surely cause problems for speakers with other L1s as well, this problem is especially important for L1 Japanese learners because Japanese and English share very distinct linguistic roots, and thus the conceptual metaphors used in each language and the cultural concepts on which they are based vary widely and significantly (Spring, 2015), likely more so than for learners of languages with closer linguistic roots, such as L1 German learners of English. However, it should be noted that this paper does not make a particular claim of L1 Japanese learners of English having a more difficult time with conceptual metaphors than L1 speakers of other languages - rather it suggests that conceptual metaphors pose a clear problem for L1 Japanese learners of English. 


\section{TEACHING METAPHORS THROUGH VISUAL MEDIA}

\section{The Benefits of Teaching Conceptual Metaphors}

As outlined in the last section, cross-cultural variation of conceptual metaphors can cause a number of problems for L1 Japanese EFL learners. A number of studies have also pointed to the fact that because of these differences and difficulties, teaching conceptual metaphors to second language learners can be beneficial (Boers, 2000; Lantolf \& Bobrova, 2014; Spring, 2018; Yasuda, 2010). For example, Boers (2000) taught EFL learners a number of conceptual metaphors that were common in English and found that it aided in their retention of vocabulary and novel figurative expressions. Lantolf and Bobrova (2014) have also argued the importance of teaching conceptual metaphors in the L2 Spanish classroom as it aids with learner retention and gives them a tool to conjecture the meanings of novel phrases and metaphors that learners encounter. Kövecses (2001) further argues that idioms can also be taught more effectively through teaching the conceptual metaphors behind them. These studies generally point to the fact that teaching conceptual metaphors to EFL learners helps them to notice the similarities in the metaphoric expressions that stem from these conceptual metaphors, and increases their ability to guess, learn, and remember such expressions.

The idea that teaching conceptual metaphors is useful for L1 Japanese learners, specifically, is supported by works such as Yasuda (2010) and Spring (2018), which have shown that utilizing explanations of conceptual metaphors helps them to remember the various meanings of phrasal verbs and/or conjecture the meanings of novel phrasal verbs more than learners who did not receive this instruction. These studies generally contribute at least part of their success to the fact that learners often don't realize the reason behind figurative expressions (i.e. conceptual metaphors) and that the learners generally cannot discern any connection between them, making them feel that figurative expressions are all arbitrary. For example, Spring (2018) showed that students generally only understood the meaning of the particle up that arises in phrasal verbs to be referring to existing in a high location, and did not realize that the particle contains extended epistemic meanings such as to move to a higher place (i.e. motion), to improve or amass (i.e. change of state or status), or to complete something to a proper degree (i.e. aspectual). However, by explaining the underlying conceptual metaphor UP IS GOOD and the reason this stems from the base meaning of high (i.e. as things amass, they are piled and the pile becomes higher, and generally having more of something is considered to be good), learners gained the ability to guess the meanings of novel phrasal verbs containing the particle up, improving much more than a control group who was not taught the underlying conceptual metaphor. 


\section{Teaching Conceptual Metaphors Through Multimedia}

Though the aforementioned studies have shown that teaching conceptual metaphors to second language learners is beneficial, they generally do not go into detail about the methods of doing so. Here, the Cognitive Theory of Multimedia Learning (Mayer, 2005) can be especially helpful, as it suggests that utilizing visual-media improves and enhances learning. Based on this theory, this paper adopts the position that multimedia learning is beneficial when teaching new conceptual metaphors to foreign language learners, but that video media, especially animations, are particularly helpful because (i) video media contains simultaneous multi-modal manifestations of the same metaphor, which enables the teacher to show the specifics of a particular concept within a particular cultural setting, and (ii) animations allow for abstractions of reality that are easy to understand, but aren't generally possible through realistic video depictions.

Mayer's (2005) cognitive theory of multimedia learning asserts that learning is assisted by multimedia presentation of the materials because people learn more deeply from words and pictures than from words alone. Specifically, Mayer (2009) says that when learning through multimedia, learners must construct new knowledge, which he describes as meaningful learning. Mayer (2009) continues to say that by undergoing meaningful learning, students develop enhanced ability to transfer problem-solving skills related to the words and information. Such problem-solving skills become particularly important when trying to teach conceptual metaphors because, as pointed out in the previous section, conceptual metaphors can manifest in a number of different metaphoric expressions. In order to understand the wide range of metaphoric expressions that can be created from a single conceptual metaphor, it is vital that learners be able to transfer the ideas of a given conceptual metaphor into the various expressions in which they might encounter it (regardless of whether the expressions appear linguistically, visually, audially or in any other mode).

Mayer (2010) gives five cognitive processes that learners must engage in when conducting meaningful learning from both linguistic and visual cues:

1) selecting relevant words for processing in the verbal working memory

2) selecting relevant images for processing in visual working memory

3) organizing selected words into a verbal model

4) organizing selected images into a pictorial model

5) integrating the verbal and pictorial representations with each other and prior knowledge

These processes all tie in especially well with teaching conceptual metaphors. Though 
conceptual metaphors often present themselves as linguistic metaphoric expressions, they are generally argued by Fauconnier (1994) and Fauconnier and Turner (2008) to utilize more cognitive processes than just verbal representations. Fauconnier (1994) argues that metaphors are built through "conceptual blends" in which various mental spaces and mappings are utilized to interpret them. Fauconnier and Turner (2008) further claim that metaphors are products of complex integrations between multiple mappings and cognitive processes. Thus, it seems that understanding metaphors already requires the integration of various types of knowledge, access to various types of working memories, and the creation of various mappings - which serve as models. Because understanding metaphors seem to involve many of the same processes as asserted by Mayer (2010), the meaningful learning that takes places through multimedia learning (Mayer, 2005; 2009) will likely be not only especially helpful, but is also necessary for learning how to understand the various metaphoric expressions arising from a single conceptual metaphor.

\section{Teaching Through Animations Aimed at Children}

Though multimedia learning can include anything from simply pictorial representations to complex audio-visual media, video media can be especially helpful for teaching conceptual metaphors to foreign language learners because such visual media often combines several modes (such as music, tone of voice, spoken word, images and visual representations) to express the same concept. According to Mayer (2003), multimedia learning works well because there is a limit to the amount of cognitive load that one channel or subsystem can process at a time. Therefore to receive the same or similar information through multiple channels increases the odds that learners will construct knowledge in meaningful ways because the more that learners pay attention to relevant material, the more likely they are to organize it into a usable mental structure that is integrated with prior knowledge (Mayer, 1999). This is then particularly beneficial to EFL teachers when trying to help learners understand a conceptual metaphor which does not exist in the L1 because the underlying concept is highlighted by the use of several modes at once, increasing awareness of not only the metaphorical expression, but of the concept behind it as well. Furthermore, since different people learn better through different modes, a combination of several modes (audio, visual, and linguistic) occurring at once can aid in the awareness and comprehension of a greater number of students. Visual representations of a conceptual metaphor can help L2 learners to understand the prototypical features of it. For example, in trying to help L1 Japanese EFL learners understand the conceptual metaphor the MIND IS A MACHINE, it would be useful to have a visual representation of a machine with moving gears, since many of the linguistic expressions of this metaphor in English have to do with gears that are turning. Therefore, even if students were to 
understand the conceptual metaphor, they would be unable to map or model it for metaphorical expressions that contain gears if they aren't aware or have not payed attention to the fact that gears are an integral part of the prototypical representation of a machine in most English speaking areas.

Another reason that video media, in particular, is especially helpful in the teaching of conceptual metaphors to foreign language learners, is that video media can help to situate a conceptual metaphor within its cultural setting. This is important for its understanding, as conceptual metaphors are created based on shared or common knowledge amongst speakers of a language in a particular culture and thus such meanings are hard to represent in formal textbooks. As Mayer (1999) points out, for knowledge to be useful, it must be integrated with prior knowledge, and Fauconnier and Turner (2008) show that for metaphors to be understood, the prior knowledge that is accessed must be shared between the producer and receiver of the metaphorical expression. Therefore, in order to understand the metaphorical expression that arises from a conceptual metaphor, a foreign language learner must have the same basic cultural understandings related to the concept as speakers of the language. This can be illustrated though an example taken from Suarez (2017), who showed that amongst episodes of the cartoon Steven Universe, romantic gestures or gestures of courtship are generally depicted from an American frame of reference (e.g. asking a partner out for a dance on the beach), as the show's creators and intended audience are Americans. These actions were generally seen to happen in conjunction with multi-modal expressions of the LOVE IS UNITY metaphor and thus part of understanding the totality of the scene and others similar to it entails both the metaphor and the American frame of courtship. Seeing actions or frames of reference together with metaphors in the target language can provide L2 learners with a model not only for the metaphor, but also for the proper terms of use and actions associated with the metaphor that are essential for understanding the L1 frame of reference. For example, if L1 Japanese EFL learners do not understand that dancing on the beach represents an act of courtship in American culture, it can lead to a misunderstanding of not only related metaphors, but also hinder comprehension of the situation and what is meant by surrounding linguistic expressions (i.e. the subsequent scene of running 'together' on the beach after dancing can be misconstrued as merely play as opposed to a romantic gesture). Using video media helps to rectify this because it also allows for a clear point of comparison between the learner's L1 and target language, helping learners to build cultural knowledge that can then be constructed into various mental mappings that will allow them to understand how various metaphoric expressions are connected to a particular conceptual metaphor.

This paper argues that amongst video-media representations, animations are especially good for teaching conceptual metaphors. One reason for this is that they allow for abstract expressions that are easily understood, but not easily recreated through real-life video 
media. For example, an animation might silhouette a character who is thinking and draw actual gears turning in his or her head, and after, an actual light bulb appears above his or her head to show the process of thinking and producing an idea respectively. While none of these would be feasible or natural in realistic video media, they are often used in animations. For instance, as Suarez (2017) points out, the Steven Universe episode Chille Tid (Jones-Quartey, 2015) shows opposing characters in a relationship depicted as being chained together, with each continually struggling to pull the other downward into their combined consciousness (depicted as the sea) for control. The more submerged the character is in the water, the less control they exert on the other. On the other hand, the controlled character is not depicted at all, completely chained under the sea [of thought]. Though this visual representation of the metaphors UNCONSCIOUSNESS IS SUBMERSION and RELATIONSHIP is a STRUGGLE is easy to understand, it would be quite impossible (or at the very least extremely costly) to depict with real actors, it is not difficult or more costly to create this effect in an animation. Such expressions of metaphors are helpful for foreign language learners in particular because of their heavy-handedness, their direct ties to the prototypes of the underlying conceptual metaphors (e.g. gears being related to machinery in the conceptual metaphor MIND IS A MACHINE), and their ability to obscure reality to easily show the blending of two mappings (i.e. RELATIONSHIP as STRUGGLE depicted through two characters pulling on chains to submerge the other) that must be combined to understand the base conceptual metaphor.

Furthermore, animations aimed at children are especially beneficial for teaching conceptual metaphors to foreign language learners. One reason for this is that children's shows must be made easy to understand, and thus many exaggerations are made in the representations of their metaphors. These metaphors are generally created multi-modally to make them as easy for children to understand as possible because they often have difficulty understanding complex mental phenomena (Mills, 2000) such as metaphors. For instance, as Suarez (2017) points out, in the Steven Universe episode, Adventures in Light Distortion (Morris, 2017), there is a segment in which a character, meant to be the embodiment of LOVE IS UNITY, announces that '[she is] made of love'. While this metaphor, or the fact that the character is meant to embody love, might be a bit difficult to understand on its own, through the use of the different modalities of animation, it is easier for the audience to understand. The scene is made markedly distinct for the viewer with an audio cue that is different from the prior tone; a light cheery chime fills a soundless background - the creators want the audience to pay attention to what's about to unfold. Visual and linguistic information then begins to contribute as the audience is presented with two newly introduced characters, one read and one blue. The two hug one another and ask about one another's well-being. A musical note gradually increases in volume, matching the amount joy the two are feeling upon reuniting; an initial kiss on the nose 
becomes the two spinning in place together in laughter. Their bodies turn into light, and eventually they merge; revealing the secret of the pair being actually one of the series' main protagonists. Up until this point, the nature of the characters' affection for one another is not verbally disclosed, but shortly after, this is made explicit through the song "Stronger than You". Prior to the song, the antagonist derides the protagonist's use of fusion, and claims to already understand it, signaling to the viewer that that nature of fusion is about to be clarified. The protagonist retorts saying that there is something more. At the same time, music begins to play, signaling the importance of the upcoming event, and then the protagonist raps, notably mixing instances of referring to itself both in the singular and plural (i.e. "[we're] back together. And I'm never..."). More explicit lyrics are used as the song goes on, "I am made of love and I'm stronger than you," eventually culminating in the victory of the protagonist. In sum, the message of the creator, FUSION equals LOVE, is made clear not only through linguistic cues (i.e. the words spoken and the lyrics of the music), but also through audio effects (i.e. periods of silence are broken with music, the tone and mood of the music), and visual cues (i.e. hugging, kissing, spinning, the two characters literally combining into one). Thus, linguistic, audial and visual expressions all work towards creating the same message, making it easier for the audience to understand no only the message, but also the conceptual metaphor on which they are all based: LOVE IS UNITY. As seen in this example, presentations of metaphors in animations aimed at children are often made easy to understand, which is in stark contrast to most animations created for adults, such as The Simpsons or Family Guy. Such works are generally created as comedy, and thus metaphors are often used subtly or in passing, as they are comedy works and it is generally considered less funny to make a joke completely obvious (Huisman, 2007).

Finally, another reason that animations aimed at children, such as Steven Universe, can be especially beneficial in the foreign language classroom is that they often have thematic consistency amongst episodes. One reason that recurring themes can be helpful is that teachers can easily find several examples of the same conceptual metaphor from the same series. This means that teachers can either choose from several examples, or provide many with the same settings and characters that will become familiar to students after several exposures. For example, the metaphor RELATIONSHIP IS A STRUGGLE occurs in a number of Steven Universe episodes, as many of the characters are often shown struggling to put aside their differences to foster their relationship(s), which is generally the key to their success in each episode. Furthermore, if a new theme or metaphor is introduced into animations aimed at children, they often deliberately alter the pace of the show through devices such as song, as exemplified by the song "Stronger than You" introduced in the previous paragraph, to help overtly communicate this change to the audience. Using clear changes in theme to highlight metaphors, such as the new idea LOVE IS UNITY that arose 
in the Steven Universe episode Adventures in Light Distortion, can be helpful to L2 learners because they are easy to notice and understand. Conversely, according to Huisman (2007) animations aimed at adults whose writing falls closer in line with standards for traditional situational comedy often present static characters in different situations, which limits the scope of metaphorical exploration because there is no chance to make connections between the same or similar characters behaving the same way or receiving the same understanding from similar situations. Furthermore, since there are fewer recurring themes in adult animations, it can be difficult for non-native speakers to understand what the cultural norms are and how the metaphor is situated within it. In fact, in many such comedic animations, the joke is often achieved by presenting a subversion of norms, which detracts from understanding how they are properly situated within a culture. For example, in The Simpsons episode Mountain of Madness (Kirkland, 1997), a scene of a fire drill is depicted, and several cultural norms are seen to be broken for comedic effect: adults panic more than expected, a character waits for his coffee to finish rather than evacuating, and the main character is the first one to successfully leave the building and he blocks the exit to secure his victory. However, most importantly, the main character is seen misunderstanding his boss' metaphorical expression for comedic effect. In this scene, his boss says, "Yes, you won alright. You won more than you bargained for," while sinister music plays, indicating that we should not interpret his meaning using the metaphor MORE IS BETTER, but instead realize that more than one bargains for is a representation of the unexpected, and thus we should interpret his meaning using the metaphor UNEXPECTED IS BAD. However, after hearing this, the main character then expresses delight at his boss' sentiment, misinterpreting his words as following the metaphor MORE IS BETTER. Because this difference is obvious for native speakers, they are invited to laugh at the ignorance of the main character. However, though this might be funny for native speakers, it is likely to simply be confusing for second language learners. Second language learners need clear, prototypical examples to follow, and this joke clearly does not provide such an example. Instead, it requires that the listener know two different metaphors and how to use navigate interpretation by using context to infer which meaning was truly intended.

\section{CONCLUSION}

This paper has presented a case that learning conceptual metaphors is difficult, but important for Japanese learners of English, and that video media can be an excellent way to do help impart the necessary information, drawing on specific examples from a children's animation, Steven Universe. First, this paper shows that learning conceptual 
metaphors in English is difficult for Japanese speakers because of not only the differences in which conceptual metaphors exist in both languages, but also in the prototypes and linguistic manifestations of metaphoric expressions built on them. As pointed out by Fauconnier and Turner (2008), understanding a metaphor requires prior knowledge that is shared between the producer and receiver of the metaphor, and thus a base of such knowledge must be created in the learner. This point is also argued by Spring (2015), who says that without these sorts of cultural understandings, learners cannot effectively communicate with speakers from other cultural backgrounds, even if they both have an adequate grasp of English as a second language. Second, this paper presented several studies that showed how beneficial teaching conceptual metaphors to EFL learners can be; learners acquire vocabulary, phrases and phrasal structures more effectively by learning about the related conceptual metaphors (Boers, 2000; Kövecses, 2001; Lantolf \& Bobrova, 2014; Spring, 2018; Yasuda, 2010;). Finally, it presented pedagogical theory that supports the idea of using multimedia to teach metaphors (Fauconnier \& Turner, 2008; Mayer, $2005 ; 2009)$ and then argued that videos and animations are particularly beneficial because of their multimodal nature, being situated in the target culture, and being created in especially easy to understand ways. In doing so, the paper also provided practical examples of how various scenes from a children's animation, i.e. Steven Universe, can be used to demonstrate and aid in the teaching of a variety of conceptual metaphors. While other videos and animations could also certainly be used to teach conceptual metaphors, animations aimed at children are generally made with easy to understand overt metaphors and contain recurring themes and metaphors, which are particularly useful for second language learners because they provide clear, consistent examples of the conceptual metaphors. This is in contrast to many animations aimed at adults, in which metaphors are often portrayed much more subtly, and presented outside of cultural norms for comedic effect.

While this paper does not contain any experimental data, it presents a theoreticallydriven account from both linguistic and pedagogical standpoints that point to the same ideas - that teaching conceptual metaphors is particularly important to Japanese EFL learners, and that videos are especially good tools for doing so. Future work should be done to test the theory outlined in this paper, potentially through experimental data. Such work could present Japanese EFL learners who learn conceptual metaphors through videos and through other means (both multimedia and non-multimedia based) to show how much of an impact the medium of instruction has on their English learning. Furthermore, more cross-linguistic and cross-cultural study is needed to determine what sorts of conceptual metaphors and which metaphorical expressions are particularly difficult for EFL learners with varying first languages. 


\section{REFERENCES}

Berendt, E. A. (2008). Intersections and diverging paths: Conceptual patterns of learning in English and Japanese. In E. A. Berendt (Ed.), Metaphors for learning: Crosscultural perspectives (pp. 73-102). New York, NY: Routledge.

Boers, F. (2000). Metaphor awareness and vocabulary retention. Applied Linguistics, 21(4), 553-571.

Dunn, C. D. (2004). Cultural models and metaphors for marriage: An analysis of discourse at Japanese wedding receptions. Ethos: Journal of the Society for Psychological Anthropology, 32(3), 348-373.

Fauconnier, G. (1994). Mental spaces. New York, NY: Cambridge University Press.

Fauconnier, G., \& Turner, M. (2008). Rethinking metaphor. In R. Gibbs (Ed.), Cambridge handbook of metaphor and thought (pp. 53-66). New York, NY: Cambridge University Press.

Forceville, C., \& Urios-Aparisi, E. (Eds.). (2009). Multimodal metaphor. Berlin: Mouton de Gruyter.

Hiraga, M. K. (2008). Tao of learning: Metaphors Japanese students live by. In E. A. Berendt (Ed.), Metaphors for learning: Cross-cultural perspectives (pp. 55-72). New York, NY: Routledge.

Huisman, R. (2007). Soap operas and sitcoms. In H. Fulton, R. Huisman, J. Murphy, \& A. Dunn (Eds.), Narrative and media (pp. 172-187). Cambridge: Cambridge University Press.

Jones-Quartey, I. (Producer). (2015). Chille tide [Television series episode]. In R. Sugar (Executive producer), Steven universe. Atlanta, GA: Cartoon Network.

Kirkland, M. (Director). (1997). Mountain of madness [Television series episode]. In J. L. Brooks (Executive producer), The Simpsons. New York, NY: Fox Broadcasting.

Kövecses, Z. (2001). A cognitive linguistic view of learning idioms in an FLT context. In M. Pütz, S. Niemeier, \& R. Dirven (Eds.), Applied cognitive linguistics II: Language pedagogy (pp. 87-115). Berlin: Mouton de Gruyter.

Kövecses, Z. (2005). Metaphor in culture: Universality and variation. New York, NY: Cambridge Press.

Lakoff, G., \& Johnsen, M. (2003). Metaphors we live by. London: The University of Chicago Press.

Lantolf, J. P., \& Bobrova, L. (2014). Metaphor instruction in the L2 Spanish classroom: Theoretical argument and pedagogical program. Journal of Spanish Language Teaching, 1(1), 46-61.

Matsuki, K. (1995). Metaphors of anger in Japanese. In J. R. Taylor \& R. E. MacLaury (Eds,), Language and the cognitive construal of the world (pp. 137-151). Berlin: 
Mouton de Gruyter.

Mayer, R. E. (1999). Research-based principles for the design of instructional messages:

The case of multimedia explanations. Document Design, 1(1), 7-19.

Mayer, R. E. (2003). Elements of a science of e-learning. Journal of Educational Computing Research, 29(3), 297-313.

Mayer, R. E. (2005). Cognitive theory of multimedia learning. In R. E. Mayer (Ed.), The Cambridge handbook of multimedia learning (pp. 31-48). New York, NY: Cambridge University Press.

Mayer, R. E. (2009). Multimedia learning ( $2^{\text {nd }}$ ed). New York, NY: Cambridge University Press.

Mayer, R. E. (2010). Applying the science of learning to medical education. Medical Education, 44(6), 543-549.

Mills, R. (2000). Perspectives of childhood. In J. Mills (Ed.), Childhood studies: A reader in perspectives of childhood (pp. 7-37). New York, NY: Routledge.

Mitroff, K. (Producer). (2017). Fusion [Television web series episode]. In R. Sugar (Creator), Steven universe. Atlanta, GA: Cartoon Network. Retrieved from https://www.youtube.com/watch?v=P3T83SKO66M

Morris, K. (Director). (2017). Adventures in light distortion [Television series episode]. In R. Sugar (Executive producer), Steven universe. Atlanta, GA: Cartoon Network.

Nabeshima, K. (2011). Nihongo no metafa- [Japanese metaphors]. Tokyo: Kuroshio Shuppan.

Nabeshima, K. (2016). Metafa- to shintaisei [Metaphor and embodiment]. Tokyo: Hitsujishobo.

Ohata, K. (2002). Phonological differences between Japanese and English: Several potentially problematic areas of pronunciation for Japanese ESL/EFL learners. Asian EFL Journal, 6(4), 1-19.

Sakui, K., \& Gaies, S. J. (2006). A case study: Beliefs and metaphors of a Japanese teacher of English. In P. Kalaja \& A. M. F. Barcelos (Eds.), Beliefs about SLA: New research approaches (pp. 153-170). New York, NY: Springer.

Spring, R. (2015). Getting in the right frame of mind to learn English as a second language. Bulletin of the Tohoku University Institute for Excellence in Higher Education, 1, 115-124.

Spring, R. (2018). Teaching phrasal verbs more efficiently: Using corpus studies and cognitive linguistics to create a particle list. Advances in Language and Literary Studies, 9(5), 125-139.

Suarez, G. (2017). Metaphors made live: Multimodal metaphor analysis in animation. (Unpublished master's thesis). Tohoku University Graduate School of International Culture Studies, Japan. 
Sugar, R. (Creator). (2013). Steven universe [Television series]. Burbank, CA: Cartoon Network Studios.

Swan, M., \& Smith, B. (Eds.). (1987). Learner English: A teacher's guide to interference and other problems. Cambridge, UK: Cambridge University Press.

Tsunoda, T. (2009). Sekai no gengo to nihongo: Gengoruikeiron kara mita nihongo [The world's languages and Japanese: Japanese seen from linguistic typology]. Kuroshio: Tokyo.

Uehara, S. (1998). Pronoun drop and perspective in Japanese. In N. Akatsuka, H. Hoji, S. Iwasaki, S. Sohn, \& S. Strauss (Eds.), Japanese/Korean linguistics (Vol. 7, pp. 275-289). Chicago, IL: University of Chicago Press.

Yamanaka, K. (2008). The tradition and transformation of metaphor in Japanese. In E.A. Berendt (Ed.), Metaphors for learning: Cross-cultural perspectives (pp. 29-51). New York, NY: Routledge.

Yasuda, S. (2010). Learning phrasal verbs through conceptual metaphors: A case of Japanese EFL learners. TESOL Quarterly, 44(2), 250-273.

Applicable level: High School and University

Keywords: metaphor theory, EFL, media assisted learning, multimedia learning, mental spaces, conceptual metaphors

Spring, Ryan (Co-author)

Tohoku University

Institute for Excellence in Higher Education

Miyagi Prefecture, Sendai city, Aoba-ku, Kawauchi 41, Japan

E-mail: spring.ryan.edward.c4@tohoku.ac.jp

Suarez, Gerard (Co-author)

University of the Philippines Diliman

Department of Education

Quezon City 1101, Benitez Hall

E-mail: gcsuarez@up.edu.ph

Received: September 21, 2018

Revised version: November 9, 2018 
How and Why to Teach English Metaphors to Japanese Learners Through Visual Media: With Practical Examples From Steven Universe

Accepted: November 25, 2018 